\title{
A mixed methods analysis of Mozambique's HPV vaccine delivery network actors.
}

\author{
Caroline Soi ( $\nabla$ soic@uw.edu ) \\ Jessica Shearer \\ PATH

\section{Baltazar Chilundo} \\ Universidade Eduardo Mondlane \\ Vasco Muchanga \\ Universidade Eduardo Mondlane

\section{Luisa Matsinhe} \\ Health Alliance International

\section{Sarah Gimbel} \\ University of Washington

\section{Kenneth Sherr} \\ University of Washington
}

University of Washington https://orcid.org/0000-0002-7213-5567

\section{Research article}

Keywords: Partnership, HPV vaccine, SNA, Mozambique, Gavi, Global health, demonstration project

Posted Date: June 29th, 2020

DOl: https://doi.org/10.21203/rs.3.rs-17473/v3

License: (c) (i) This work is licensed under a Creative Commons Attribution 4.0 International License.

Read Full License

Version of Record: A version of this preprint was published at BMC Public Health on June 5th, 2020. See the published version at https://doi.org/10.1186/s12889-020-08958-1. 


\section{Abstract}

Background: Global health partnerships have expanded exponentially in the last two decades with Gavi, the Vaccine Alliance considered the model's pioneer and leader because of its vaccination programs' implementation mechanism. Gavi, relies on diverse domestic and international partners to carry out the programs in low- and middle-income countries under a partnership engagement framework (PEF). In this study, we utilized mixed methods to examine Mozambique's Gavi driven partnership network which delivered human papillomavirus (HPV) vaccine during the demonstration phase.

Methods: Qualitative tools gauged contextual factors, prerequisites, partner performance and practices while a social network analysis (SNA) survey measured the partnership structure and perceived added value in terms of effectiveness, efficiency and country ownership. 40 key informants who were interviewed included frontline Ministry of Health workers, Ministry of Education staff and supporting partner organization members, of whom 34 participated in the social network analysis survey.

Results: Partnership structure SNA connectivity measurement scores of reachability (100\%) and average distance (2.5), were high, revealing a network of very well-connected HPV vaccination implementation collaborators. Such high scores reflect a network structure favorable for rapid and widespread diffusion of information, features necessary for engaging and handling multiple implementation scales. High SNA effectiveness and efficiency measures for structural holes (85\%) and low redundancy (30\%) coupled with high mean perceived effectiveness (97.6\%) and efficiency (79.5\%) network outcome scores were observed. Additionally, the tie strength average score of 4.1 on a scale of 5 denoted high professional trust. These are all markers of a collaborative partnership environment in which disparate institutions and organizations leveraged each entity's comparative advantage. Lower perceived outcome scores for country ownership (24\%) were found, with participants citing the prominent role of several out-of-country partner organizations as a major obstacle.

Conclusions: While there is room for improvement on the country ownership aspects of the partnership, the expanded, diverse and inclusive collaboration of institutions and organizations that implemented the Mozambique HPV vaccine demonstration project was effective and efficient. We recommend that the country adapt a similar model during national scale up of HPV vaccination.

\section{Background}

Health program implementation especially in low-and middle-income countries (LMICs), requires the involvement of different types of actors from different sectors(1). Disparate individuals from different types of organizations and institutions, spanning multiple and hierarchical health system levels, such as community, health facility, regional, national and international all have a role to play(2)(3). This diversity in actors relies on various relationships and interactions amongst all players involved in program operationalization. Partnership, which is defined as a collaboration with the mission of accomplishing a common goal either contractually or non-contractually, is a key type of such relationships(4). 
Partnerships, have traditionally existed at the country level amongst different implementing entities, however the global health partnerships (GHPs) phenomenon, is more recent, with most such partnerships being created in just the last two decades(5). Despite their novelty, GHPs have expanded exponentially and gained broader relevance to the extent that they are now a salient feature of health program implementation in LMICs(6)(7). Consequently, partnership has become a significant health program implementation determinant in these settings (8) and the broader implementation science (IS) field formally recognizes the study and measurement of partnerships as a core component of implementation research(9) (10) (11). The field's practitioners argue that inter-organizational collaborations create larger pools of resources which lead to accelerated adoption, institutionalization and sustainment of global health programs(12).

Gavi, the Vaccine Alliance (Gavi), is a GHP that was set up with the agenda of increasing availability and accessibility of new and underutilized vaccines in LMICs (13). Founded in 1999, the public private partnership brings together four founding organizations, the Bill and Melinda Gates Foundation (BMGF), World Bank, World Health Organization (WHO) and the United Nations Children's Fund (UNICEF) in a set up designed to leverage each organization's unique technical expertise in the global arena. Additionally, pharmaceutical companies that manufacture vaccines, donor and recipient governments, civil society organizations, research and technical institutes are also members of the alliance(14). In this partnership model, Gavi does not place implementation support teams for its sponsored programs in countries but instead relies on both in- and out- of country partners under its partnership engagement framework (PEF) mechanism. WHO and UNICEF are the principal in-country implementation partners undertaking majority of PEF activities, while other organizations' involvement depends on countries' immunization programs' capacity and needs (15).

Gavi financial support for new vaccine introductions (NVIs) began in 2000, with availability of funds for the combined diphtheria, pertussis (whooping cough), tetanus and Hepatitis B (DPT-HepB) vaccine. Subsequently the number of supported vaccines increased to the current eleven; one of which is the Human Papillomavirus (HPV) vaccine(16). Its inclusion in 2011, was however marked by an unprecedented requirement for countries to first implement a demonstration project prior to national scale-up, in order to gauge effectiveness of possible delivery models. The demonstration project was deemed necessary due to the novel target age group of $9-13$ years that falls out of routine country national immunization programs' (NIP) target age group of 9-24 months. Most LMICs do not have an adolescent specific health care service and therefore lack a health service delivery system for this target group(17). HPV vaccine introductions were therefore being conducted in two phases, the demonstration project and the national roll out, each with its own set of decision making, planning and execution processes (18). While Gavi has had a record of success in accelerating the national adoption of the other new vaccines(19), HPV vaccine introduction encountered a challenge of slow adoption. Twenty three countries completed demonstration projects by December 2016, but only 6 had advanced to national scale up phase by Dec 2017, a stark contrast to Gavi's planned target of 8 nationwide HPV vaccine introductions by 2015(20). Despite Gavi's effort to accelerate country uptake by removing the required demonstration project phase(21), only 18 LMICs countries have introduced HPV vaccines into their NIPs 
to date. The lagged adoption has been attributed to multiple factors, however an important barrier is the dearth in published country specific HPV vaccine demonstration project evaluation findings in the literature(22).

Social Network Analysis (SNA) is a modern sociology technique, that provides theory and tools for the visualization and measurement of interactive relationships amongst people or items. SNA is widely applicable to relational patterns created by any tangible or non-tangible content(23). Because such patterns form network structures that may act as facilitators or constraints to the achievement of a networks' objectives, SNA findings can be utilized to address a network's structure bottlenecks or leverage its strengths(24). Health services delivery researchers are increasingly harnessing SNA tools to understand diverse aspects of health systems. Organizational governance has proved to be an opportune topic for this type of inquiry which makes inconspicuous communication and collaboration patterns visible, thus enabling the study of key strategic and managerial decision-making information flows amongst important players within a health system (25) (26).Despite this expansion in SNA utilization, its use in LMIC health systems governance research is still nascent (27) (28). One aim of our study is to contribute to this expanding health systems SNA body of knowledge, through applying the techniques to study a complex vaccine delivery collaboration. We argue that SNA techniques can be used by global health implementation researchers to visualize a partnership network's structure and measure its connectivity to understand how rapidly information diffuses through it. Furthermore we correlate SNA connectivity metrics scores with a network's ability to effectively engage with and handle multiple scales (e.g. levels and sectors of the health system), combine and integrate different forms of knowledge as well as its capacity to anticipate and cope with uncertainties and surprises. We thus demonstrate how SNA techniques can be used for decision making when establishing a global health program implementation partnership. Our second objective is to fill the existing gap in documentation of country specific HPV demonstration project research findings in the literature. We present a case study conducted on Mozambique's HPV vaccine delivery demonstration project. We leveraged the Gavi Full Country Evaluation (FCE) partnership framework (Figure 1) (28) to test the contribution of network structure on the added value of the project's partnership.

The remainder of this paper is organized as follows: Section 2 addresses the study setting, describes the Gavi FCE evaluation partnership framework dimensions and details the study design, data collection and data analysis procedures. In section 3 we describe the results in detail and then discuss them in section 4. Finally, we conclude the paper in section 5 and offer recommendations for national scaling up of Mozambique HPV vaccination.

\section{Methods}

\subsection{Study Setting}

The 2014 to 2018 Gavi FCE, was a prospective in-depth assessment of inputs, outputs, outcomes and impact of its financial support to LIMC immunization programs. One key FCE research question explored 
the role of Gavi's partnership model on decision making, planning, implementation and technical support in delivery of country immunization services. This paper presents findings from the case study undertaken in Mozambique in response to this partnership research question.

\subsubsection{The case}

The Mozambique HPV vaccine demonstration project, whose objective was to test a model for HPV vaccine delivery to girls aged between 9 and 13 years, was undertaken during two years, 2014 and 2015 . It was implemented in three districts that were chosen to represent the three socioeconomically diverse geographical regions of the country. These were Manhiça, Manica and Mocímboa da Praia in Southern, Central and Northern regions respectively. Funding was obtained from Gavi for Manhiça district while the Government of Mozambique (GoM) funded the project in the other two districts. The tested delivery model was primarily school based whereby health workers administered the vaccine to girls in schools. Periods of one week were predetermined and utilized for the delivery of each dose. In the first year (2014) three doses were delivered in May, June and November in alignment with the then WHO recommended HPV vaccine administration schedule of 0,1 , and 6 months intervals. In the second year (2015) the WHO guidelines had changed to two doses to be given at 0 and 6 months and the vaccine was administered in June and November(29).

\subsection{The Gavi FCE Partnership Framework}

Our study was oriented by the Gavi FCE partnership framework, which was developed through integration of concepts from public administration, organizational science and network analysis, resulting in five causally related partnership evaluation dimensions (Figure 1). The framework differs from predecessor partnership evaluation frameworks, by placing the role of a partnership's network structure at the core of its effectiveness. It postulates that effective partnerships require appropriate partnership network structures and proposes the empirical measurement of network structure, using SNA metrics, as a tool to inform partnership formation(28). It hypothesizes that the framework's structure dimension will be highly predictive of a partnership's performance. This assumption is based on the social network diffusion theory(23) which explains how network structures act as either facilitators or barriers for adoption of novel practices. According to the theory, network-level structure outcomes for connectivity, efficiency and effectiveness, are determined by relationships between network actors. These relationships usually involve a relational content (23), such as information or resources, that can be measured using SNA metrics(23). In this study technical assistance information, was the relational content measured, in order to determine the structure of collaboration relationships amongst Mozambique's HPV vaccine demonstration project implementation partners.

\subsection{Study design}


Mixed methods were used to study the partnership evaluation framework's five dimensions detailed in table 1. Qualitative tools described the partnership's contextual factors and prerequisites, partner performance and practices, so as to facilitate the understanding of its context, how and why partners perform as they do and how and why partnership practices are what they are. SNA measured the effectiveness and efficiency of the partnership's network structure while a survey assessed partners' perceptions about the added value of HPV vaccine implementation collaboration (Figure 2).

\section{Figure 2: Research methods and partnership dimensions studied}

\subsection{Data Collection}

Institutional Review Board (IRB) approvals were obtained from University of Washington and Mozambique Ministry of Health prior to data collection. A team of Gavi FCE researchers, collected data at central level and in all three demonstration districts, during the two years that the HPV vaccine demonstration project was implemented.

\subsubsection{Qualitative data}

Three methods were used to gather qualitative data i) document review ii) direct observations iii) key informant interviews (KIIs). A broad range of documents were reviewed including all Mozambique HPV vaccine demonstration project vaccine grant proposals, HPV demo project budgeted plans, Mozambique Gavi business plan and partnership engagement framework, Gavi HPV vaccine demonstration project guiding documents, minutes of meetings held by the NIP and partners, notes from direct observations, terms of reference for the different HPV vaccine demonstration project related committees/technical working groups, NIP programmatic evaluation documents, NIP strategic plans, NIP audits and financial reports. Information gathered from document review were used to refine the questions in the KII topic guide.

Direct observations were conducted through participation(30) in all HPV vaccine demonstration project meetings ranging from NIP technical working group meetings; subcommittee meetings focusing on, for example, cold chain management; national immunization technical advisory group meetings (NITAG); and Inter Agency Coordination Committees (ICC) meetings. Additionally, events such as trainings, supervision visits, the official launch and all implementation activities for HPV vaccine demonstration project in the three demonstration districts were attended. Information gathered from direct observations that respond to the evaluation aspects of the five dimensions of the partnership framework were used to further refine the questions in the KII topic guide.

KII respondents were identified through a two-pronged sampling approach. First, was the comprehensive approach targeting all known NIP stakeholders and second the chain referral (snow ball) approach targeting other key informants (KIs) as they were referred by those already sampled(31). Known stakeholders refer to institutions and organizations that had been distinguished during document review and direct observations. Samples were drawn from the following groups within these identified entities: 
health facility immunization staff, district immunization staff, district education staff, provincial immunization staff, provincial medical heads, central $\mathrm{MOH}$ level immunization program staff, staff from research institutions, non-Governmental organizations (NGOs), bilateral and multilateral institutions that supported the NIP during all the HPV vaccine demonstration project phases. A semi-structured openended interview guide was developed and used for all respondents with probing techniques being applied whenever the need arose. Interviews were conducted in the place of convenience to the key informant, usually in their office. Appointments were arranged through both email and phone. Consent forms and topic guides were shared with respondents prior to interviews which were documented through note taking and audio recording.

\subsubsection{Social Network and Perceived Outcomes data}

Both SNA and perceived outcomes data were collected through a single two-section structured questionnaire (Appendix 1). The positional strategy(23) was used to specify the network boundary with actor identification being based on their positions in institutions and organizations that were involved in HPV vaccine demonstration project implementation. Each actor was asked: "With whom did you work with on the HPV vaccine demonstration project?" This process is referred to as a 'name generator' in social network analysis(23). For documentation of the relational content, survey respondents were asked whether they had received or provided technical assistance. In order to measure tie strength respondents were asked to rate their level of professional trust and satisfaction on a scale of one to five. The professional trust question was "when working with the individual you have named, do you trust that he/she has the ability to respond to what you requested for and to do and complete what they have promised to do?"

The perceived outcomes section contained a set of questions about the Kls' perceptions of their working relationships with other HPV vaccination implementing partners. These questions were adapted from Provan et al.(32) and organized according to perceived benefits and drawbacks of working together. Respondents were asked to choose if the benefit or drawback had occurred or had not occurred when they worked together as a partnership with HPV vaccine demonstration project implementation partners. Probing was employed to capture reasons for the choice provided by the informant and notes taken to document responses.

\subsection{Data Analysis}

The units of analysis for the qualitative segment of our study, were the individuals, institutions and organizations directly involved in the implementation of the Mozambique HPV vaccine demonstration project. Audio recorded data was transcribed into texts by known professional transcribers with experience in transcribing other audio recorded data for the Mozambique Gavi FCE. Nvivo software was used to facilitate a theme-based analysis as per the five dimensions of the Gavi FCE partnership conceptual framework. A preliminary codebook was developed and responses to the partnership framework dimension's research questions sought and given their own code. Following coding, a report of 
each code was produced, read, and re-interpreted resulting in a synthesis of findings related to each dimension.

Two sets of hypotheses, listed in table 2, guided SNA measurement of the partnership network structure. The first set relate network structure connectivity to WHO health system governance characteristics, an approach originally described by Blanchet et al(33). The second set stem from SNA theory of diffusion and relate network structure to network efficiency and effectiveness (21).

The individual was the unit of analysis for both social network and perceived outcome analyses. Data collected from the network survey was entered into a spreadsheet matrix in MS Excel. Each reported working relationship, or "tie," was weighted according to the key informant's rating of relationship trust while the technical assistance exchange tie was entered as binary. The resulting spreadsheet contained three asymmetrical, undirected network matrices which were imported into UCINet software(34) for analysis. Descriptive network maps were created using the NetDraw(35) application within UCINet software with nodes being color coded according to node attributes from the survey. Tests were run for each SNA metric associated with the hypotheses behind our SNA (Table 2). Five metrics namely reachability, distance, centralization, betweenness and density measured network structure's connectivity while three metrics, structural holes, redundancy and homophily measured its efficiency and effectiveness. SNA metrics that measure the networks structure efficiency and effectiveness are also referred to as network outcome measures.

Data from the perceived benefits and drawbacks survey section was entered in the same excel spreadsheet as the network data and proportional scores calculated for each survey response. In addition, the benefits and drawbacks were stratified into effectiveness, efficiency and country ownership and a mean score calculated for each stratum.

We utilized an iterative triangulation process, in which all the three types of data were analyzed and reanalyzed, to construct patterns and facilitate interpretation.

\section{Results}

\subsection{Descriptive statistics}

A total of $40 \mathrm{KIls}$ were conducted at national, provincial, district and health facility levels in the three HPV vaccine demonstration district sites in the country (Table 3). Of these study participants, 34 responded to the social network and perceived outcomes surveys. Majority of those interviewed were from the Ministry of Health (MOH) $(55 \%)$ and the Ministry of Education (MOE) (15\%) with a larger proportion (35\%) being from the district level

\subsection{Gavi FCE partnership framework dimensions' detailed results}

\subsubsection{Contextual factors and prerequisites}


We found that, Gavi plays a key role in driving Mozambique's HPV vaccination delivery partnership, nevertheless other significant contextual factors also emerged as key drivers of the partnership. These are; the country's first lady's involvement as a champion, Gavi's requirement for the NIP to demonstrate feasibility of its HPV vaccine delivery model and schools as the primary location of HPV vaccine administration.

Gavi's partnership model, is the main driver of the country's national immunization collaboration which according to interviewed informants historically stemmed from the country becoming a beneficiary of Gavi grants in 2001. The two core Gavi partners WHO and UNICEF, whose task within the Alliance, are to provide in-country implementation support, were referred to by NIP staff as the "traditional partners". Each organization is known for specific roles, WHO for technical guidance and UNICEF for logistics and supplies, a fact that we learned has influenced the NIP to adopt the practice of allocating specific roles to potential partner organizations that express interest to collaborate with it.

"We are used to working with WHO for technical guidance. UNICEF they usually support us for vaccine logistics and supply" NIP

Two other organizations, VillageReach an international non-governmental organization (NGO) and Fundação para o Desenvolvimento da Comunidade (FDC) a local organization were also considered as "usual" NIP partners and had supported immunization activities for more than five years prior to the HPV vaccine demonstration project launch. Further investigation revealed that that these two organizations had strong ties to Gavi. VillageReach is an American based organization whose funding comes from the BMGF, a founding partner of Gavi. In addition, one of its founding board members has been Gavi's chief executive officer for seven years, from 2011 to date. FDC's founding president had also previously been the chair of Gavi's board for a decade, from its inception in 2001 until 2009. Results qualitative data triangulation, revealed the importance of these Gavi links, to VillageReach's and FDC's participation as NIP's partners in Mozambique's HPV vaccine delivery demonstration project implementation.

"Invitation for VillageReach (to be NIP partner) was explicit. Especially after the head of NIP understood VillageReach's work and its relationship with Gavi. She (NIP head) was initially new. The chief executive officer of Gavi used to be board member of VillageReach from the inception of VillageReach. We were invited when they realized the relationship we had with Gavi and the information that VillageReach possesses about Gavi" (Civil Society Organization)

"...for example FDC was already interested in HPV vaccination introduction, from before because its president Machel was a member of the Gavi board for many years" (Research Institute)

In the year prior to the launch of the HPV vaccine demonstration project, Mozambique's then first lady assumed leadership of the Forum of African First Ladies Against Breast \& Cervical Cancer and hosted a conference in Maputo, the country's capital(36). This position propelled her to become a HPV vaccination champion in both the continent and in-country, with subsequent impact on HPV vaccination pilot partnership. Her championship position influenced the NIP and $\mathrm{MOH}$ to take on a leadership role as 
opposed to the participatory one that both entities had assumed during HPV vaccine grant application writing. Furthermore, $\mathrm{MOH}$ leveraged government funds to carry out demonstration activities in two additional districts, instead of only one district that Gavi was funding. Another outcome of $\mathrm{MOH}$ leadership, was the disbursement of HPV vaccine introduction grant (VIG) funds from Gavi through $\mathrm{MOH}$ and not to Gavi in-country partners, WHO and UNICEF as had happened previously, with pneumococcal vaccine (PCV) introduction grant. KIs noted that, by assuming a leadership role, the $\mathrm{MOH}$ became better placed to negotiate how Gavi funds would be received in-country. The expansion in number of demonstration project sites impacted on the HPV vaccination pilot project partnership because it led to increase number of players.

A couple of other contextual factors unique to HPV vaccine delivery model, led to a partnership which differed compositionally from the one observed during other Gavi funded new vaccine introductions in Mozambique. First was Gavi's requirement for the inclusion of an assessment component to examine feasibility of the delivery model that would be tested during the demonstration project. For this purpose, two research institutions, the Manhiça Research Center (CISM) and the country's National Institute of Health (INS) were included in the partnership, to lead assessments in Gavi and Government funded districts respectively. The second factor was the nature of delivering HPV vaccine in schools necessitating the involvement of MOE in the partnership. MOE personnel had to carry out specific HPV vaccination activities at all levels from national to provinces, districts and schools.

\subsubsection{Partnership Structure}

The SNA results for reachability, distance, centralization, betweenness, density, structural holes, redundancy, homophily and average trust are shown in table 4. The network structure was found to contain a total of 50 actors (nodes) and 164 ties.

The reachability score is $100 \%$ meaning that there is at least one path connecting all actors in the network and each can be reached from whichever point one starts from (figure 3). The distance score, which is defined as the average number of edges in the shortest path between pairs, at 2.52 is short. Shorter distance in SNA is commensurate with faster and more accurate information flow. Combining the two SNA metrics scores with our first WHO health system governance characteristic hypotheses (Table 2) we can infer a partnership that has the capacity to effectively engage with and handle multiple

scales. The perceived outcome survey scores corroborate this finding (Table 5). At $97.6 \%$, the effectiveness average score was the highest of all outcome survey mean scores. Furthermore, we noted

$100 \%$ partners' agreement to three perceived outcome questions; 1 ) HPV vaccination partnerships ability for better execution, 2) better quality and improved response to challenges when they worked with multiple types of entities and 3) organizational hierarchical levels.

For the second WHO health system governance characteristic hypotheses, the centralization score was found to be neither low nor high at $48 \%$, and average betweenness was 37.24 with a large standard 
deviation of 110.1. These scores are consistent with the network's outdegree statistics that revealed

three outlier actors numbers 2, 5 and 24 (figure 3 ), around which the network is centralized. While actor number 2 had the highest outdegree score, this centralization value, means that the partnership is not highly centralized around 1 focal actor (e.g. EPI program). In addition, the network structure connectivity

scores support the existence of effective relationships between these three key actors, indicating that the partnership could coordinate and respond rapidly to challenges. When triangulated with perceived

outcomes survey results, we found a concordance as $100 \%$ of respondents, answered affirmatively for the question on their perception of HPV vaccination partnership's capacity to respond to challenges which had arisen during project implementation processes (Table 5). Qualitative data further supported the finding (see quotation below).

"The involvement of many organizations was very advantageous because we as the district directorate of health would not have been able to undertake all the activities within the short time that we had to prepare. The partners and their support helped us to reach where we would not have reached, for example sometimes they gave us fuel when we didn't have and even one hired a boat to reach some islands" (District Health Directorate)

The third WHO health system governance characteristic is the capacity to combine and integrate different forms of knowledge whose hypotheses (Table 2) are based on density and reachability across different spheres and entities. According to SNA diffusion theory, actors in very dense networks have difficulty in accessing diverse forms of knowledge; however density is important for the effective transfer of complex knowledge(37). This network has a low density score of 0.1338 , which taken together with the observed diversity of types of entities in the network, distinguished by different colors in figure 3 , and the $100 \%$ reachability score, mean that actors in this partnership are well positioned to receive new types of information. Further support for this finding comes from contextual qualitative data. KII respondents talked of the implementing partnership for HPV vaccine, being compositionally different from implementing partnerships for traditional NIP vaccines which target children below 22 months of age compared to HPV vaccine's novel target age group of 9-13 years.

"The target group for HPV vaccine is different so we have to work with different collaborators, for example the ministry of education and partners in the community that helped us to pass the message" (District Health Directorate)

\subsubsection{Partnership performance, practices and outcomes}

The last three dimensions are interpreted here jointly because our conceptual framework postulates that a partnership's structure determines its performance, practices and consequently the outcomes. SNA measures have so far revealed a network characterized by high overall connectivity that is favorable for rapid and widespread diffusion of information. In addition, trust within the partnership is very high as evidenced by the high tie strength average score of 4.056 which is very close to the upper limit of five on 
the scale that respondents had been asked to rate professional trust on. Network outcome SNA measures (described in table 2) unveiled an efficient network structure characterized by a high number of structural holes and less redundancy. Majority (85\%) of the nodes in the network require only 2 or 3 paths to reach them and $70 \%$ have only one way to connect with other nodes meaning that redundancy is only $30 \%$. The network was also found to be heterogenou $s$ with a homophily E-I index scores of 0.195.

On triangulation with qualitative and perceived outcomes data so as to facilitate interpretation we found that these topological features of the network influenced partnership practices and subsequently the outcomes. The partnership's structure heterogeneity significantly influenced partnership practices. The avoidance of duplication of activities or partner organizations focusing on the same activities in the same geographical area emerged as very key to the effectiveness and efficiency of this partnership. Respondents at all levels emphasized the role of regular meetings in the form of a formalized NIP technical working group (TWG) at national level and regular meetings chaired by the head of health at provincial and district levels. Specific roles for specific partner organization was another attribute that respondents repeatedly stated. Remarkably each partner organization was known for a specific role in this partnership. Beyond WHO and UNICEF's earlier stated roles VillageReach was known as a logistical support partner, FDC for community mobilization and GlaxoSmithKline (GSK) usually supported printing of training material and health worker job aids. Perceived outcomes survey scores added strength to these findings with $88 \%$ of respondents agreeing that the partnership leveraged each partner organizations' comparative advantages.

".......the duplication of activities does not occur because each organization presents its activities to the directorate and the directorate tells them where they can work. Apart from that we have regular coordination meetings" $\mathrm{MOH}$ provincial Directorate

Lower agreement perceived outcome scores were noted for the questions on country ownership (79\%), reduction in financial cost of process (74\%) and better allocation of each organization's financial resources (62\%). Many district level respondents expressed their dissatisfaction in the sufficiency of funding that had been availed to them for HPV vaccination activities, with the situation being worse in the districts that were not funded by Gavi and had to depend on only $\mathrm{MOH}$ funds. While some respondents noted that partner organizations had stepped in and helped a lot, especially with in kind donations, many talked of lack of funding for outreach activities for finding non-school attending girls in communities as a major challenge. Correspondingly, the highest perceived outcomes drawbacks score was that of country ownership at $24 \%$. Several issues were mentioned regarding country ownership but featuring prominently was the preference for a country based partner organization. Respondents expressed their unhappiness on the inclusion of a non country-based partner in the HPV implementation partnership. Language barrier and lack of contextual knowledge were mentioned as some of the problems of the specific technical assistance that was provided by the particular partner who was considered foreign. The lack of participation in regular technical working group meetings was also noted as a hindrance to individuals based outside the country contributing effectively to the partnership. This is because TWG meetings was the forum where most of the partnership communication took place with updates on progress on

Page $12 / 25$ 
processes being made, important discussions taking place and key decisions being made during the meetings. Short visits to the country to provide technical assistance were said to be ineffective by survey respondents and were even blamed for having largely contributed to the delay in the accomplishment of some HPV vaccination pilot implementation phase deliverables.

\section{Discussion}

Delving into the Mozambique HPV vaccination implementation stakeholder relationships in this case study, has revealed the importance of balance between donor and government influence, the necessity for adaptability to changing needs and the value of country ownership for an effective vaccine delivery partnership.

We observed a partnership that was equally driven by the $\mathrm{MOH}$ as well as the influence of the global Gavi partnership model. The balance between Gavi and Government of Mozambique influences during the implementation of this pilot led to remarkable effectiveness and efficiency results. The perceived outcome survey mean effectiveness score was quite high at $97.6 \%$ and the mean efficiency was $79.5 \%$. Partnership composition and practices were equally driven by both entities resulting in a complementary relationship that engendered a favorable collaborative environment in which the best that each institution had to offer was leveraged. The Gavi partnership model of having specific core partner roles guided the HPV partnership to adapt these principals and as a result each organization's competencies were optimized and redundancies in terms duplication of partner activities were avoided. These conditions created a conducive environment for the successful testing of a challenging vaccine delivery model for a novel target group in three different Mozambican socioeconomic contexts with the outcome of important knowledge being gained for national scale up planning. Had Gavi's influence been dominant and the original Gavi decision followed, the HPV vaccination pilot would have taken place in only one district representing only one Mozambican economic and religious context and learnings from the different contexts that the other two districts offered, would have been missed. Similar significance of country level influence in decision making for introduction of new vaccines is documented in the literature(38) (39).

Another salient finding emerging from this study is the importance of a flexible partnership to adequately respond to unpredictable events and evolving priorities. The expansion of the Mozambique demonstration project that was originally planned for just one district to three districts happened in a short period of time, within just six months prior to the launch of the demonstration project. The ability for the partnership to adapt and bring on and integrate new members to the implementation collaboration was outstanding. This finding not only agreed with the SNA hypotheses that we had adapted from Blanchet et al regarding the second characteristic of the WHO health system governance characteristic number two (table 2) but with our SNA results too. Our results, which align with previous study findings (40)(41), clearly demonstrate that a partnership whose structure is moderately centralized, around few key diverse players, has a higher capacity to coordinate actors and provide rapid response. Similarly, rapid response occurs when the key diverse players have the ability to reach all actors across the different 
entities in the network. In addition, another learning was the function of an innovative intervention requiring additional roles and further leading to the expansion of the partnership. Again, the partnership was malleable and successfully integrated the necessary research institutions and ministry of education for the purpose.

The third and final outcome measure of our study was the country ownership for which perceived outcome survey score at $79.5 \%$ at was among the lower scores. A salient factor that was elucidated was how the location, in or out of country, of a technical assistance provider affects the outcome of their support. Specific barriers that were encountered by the out of country international partner and which we have highlighted in our results section, are particularly informative and relevant for Gavi to consider when assessing potential technical assistance providers for countries in the current era of the partnership engagement framework (PEF).

In applying the Gavi FCE partnership framework we have found it to be a particularly useful tool for conducting a comprehensive partnership evaluation. This is because unlike previous predecessor partnership evaluation frameworks, namely the traditional and Brinkerhoff(42), the FCE framework approach is more wholistic resulting in consideration of an expanded set of partnership characteristics which influence partnership performance outcomes. While all three frameworks invariably describe the causal chain nature of the partnership characteristic from the contextual factors and prerequisites to the outcomes, the inclusion of the partnership structure together with the provision for the use of SNA tools to study it, highly enhanced the framework. These components of the FCE framework offer the possibility of unmasking partnership attributes that may not be overt.

The utilization of SNA tools in our study enabled us to visualize the otherwise invisible constellation of relationships that make up Mozambique's HPV vaccine delivery partnership network. The image of the network structure facilitated a rapid identification of key players within the implementation collaboration. As in other studies(43)(44) , SNA measurements demonstrated the partnership network structure's effectiveness and efficiency in information flow and innovation adoption. Such information can only be attained using SNA methods thus making it a powerful methodology to inform other vaccine delivery endeavors and health program partnerships. Furthermore, the FCE framework guided our utilization of mixed methods which allowed for a broader analysis and exploration of the partnership. We therefore recommend the use of the Gavi FCE framework for evaluation of global health partnerships.

\subsection{Strengths and Weaknesses}

Our study's participation rate was quite high with 40 individuals from different entities and different health system levels responding to both the network and perceived outcomes survey. This is a relatively large sample size especially for the qualitative data component; however, the accuracy of network data rely on a full census of a network and this study's response rate may lead to underestimations of network density in particular. Ties beyond the set boundary were not explored and there might be missing data that was not captured. Mixed methods captured different types of data that were triangulated, and this facilitated interpretation.

Page $14 / 25$ 


\section{Conclusion}

Global health implementation draws together diverse international entities for the purpose of enhancing health intervention adoption and institutionalization. The resulting complex collaborations' efficiency and effectiveness can be evaluated so as to provide knowledge for decision makers tasked with creating such partnerships. Harnessing mixed research methods with the use of several types of qualitative methods including document review, participant observation and key informant interviews in combination with SNA and perception surveys can highly augment the assessments. This study's scientific contribution is the illustration of how disparate research methods can be utilized together to conduct in-depth examination of pertinent partnership dimension components. Even though the results of the study may have limited applicability in settings whose vaccination services are organized differently from those of Mozambique, its finding are generalizable to low and middle-income countries with similar socioeconomic features.

Finally, the study revealed that while there is room for improvement on the country ownership aspects of the partnership, the expanded, diverse and inclusive collaboration of institutions and organizations that implemented Mozambique's HPV vaccine demonstration project was effective and efficient and we recommend that the country adapt a similar model during national scale up. Our results also can also be used to orient Gavi's PEF partner selection for Mozambique and other countries in a similar context. For future work, the methods utilized in this study will be replicated by our implementation research teams working in other health program areas in Mozambique and other LMICs.

\section{Declarations}

\section{Ethics approval and consent to participate}

Ethical approval for the Gavi FCE, which includes this study, was secured from the University of Washington Institutional Review Board and the Mozambique Ministry of Health National Bioethics Committee. Written consent was obtained from all study participants. None of the participants was under 16 years old.

\section{Consent for publication}

This manuscript does not contain individual person's data in any form so consent to publish is not applicable.

\section{Competing interests}

The authors declare they have no conflicts of interest.

\section{Funding}


This work was supported by Gavi, the Vaccine Alliance. The funders had no role in study design, data collection and analysis, decision to publish or preparation of the manuscript

\section{Availability of data and material}

The datasets generated and analyzed during this study are not available because the interview and survey files are personally identifiable. The social network and outcome survey data files contain names and key informant interview files would be identifiable to a person familiar with the Mozambique health system given that study participants were identified by their specific roles and responsibilities within the health system.

\section{Authors' contributions}

JS, CS, BC, VM, LM and SG were involved in the conception and design of the study. CS, BC, VM and LM were involved in data acquisition. CS and JS analyzed the data. CS drafted the first version of the manuscript. JS, BC, SG and KS made critical revisions to the manuscript. All authors read and approved the manuscript.

\section{Acknowledgements}

We would like to thank all the Gavi FCE team members and all key informants and survey study participants.

\section{Abbreviations}

BMGF: Bill and Melinda Gates Foundation; CISM: Centro de Investigação de Saude da Manhiça; CSO: Civil Society Organization; FCE: Full Country Evaluation; FDC: Fundação para o Desenvolvimento da Comunidade: GHPs: Global Health Partnerships; GOM: Government of Mozambique; GSK: GlaxoSmithKline; HPV: Human papillomavirus: ICC: Inter-agency Coordination Committee; INS: Instituto Nacional de Saúde; KIIs: Key Informant Interviews; LICs: Low Income Countries; LMICs; Low and MiddleIncome Countries; MOE: Ministry of Education: MOH: Ministry of Health; NGOs: Non-Governmental Organizations; NIP: National Immunization Program; NVIs: New Vaccine Introductions; PCV: Pneumococcal Vaccine; PEF: Performance Engagement Framework; SNA: Social Network Analysis; TWG: Technical Working Group; UNICEF: United Nations Children's Fund; VIG: Vaccine Introduction Grant; WHO: World Health Organization

\section{References}

1. Kellam SG. Developing and Maintaining Partnerships as the Foundation of Implementation and Implementation Science: Reflections over a Half Century. Adm Policy Ment Health Ment Health Serv Res. 2012 Jul;39(4):317-20. DOI: 10.1007/s10488-011-0402-8 
2. Brown CH, Kellam SG, Kaupert S, Muthén BO, Wang W, Muthén LK, et al. Partnerships for the Design, Conduct, and Analysis of Effectiveness, and Implementation Research: Experiences of the Prevention Science and Methodology Group. Adm Policy Ment Health Ment Health Serv Res. 2012 Jul;39(4):301-16. DOI: 10.1007/s10488-011-0387-3

3. Lappalainen PH. Conflicts as Triggers of Personal Growth: Post-Traumatic Growth in the Organizational Setup. SciMedicine J. 2019 Sep 1;1(3):124-36. DOI: 10.28991/SciMedJ-2019-0103-2

4. Griffiths J, Maggs H, George E. Stakeholder involvement. Doc Téc Prep Para El Even Conjunto OMSForo Económico Mund Sobre Prev Las Enfermedades No Transm En El Lugar Trab Ginebra Organ Mund Salud. 2007;

5. Daems R, Edith Maes DBA. Global Health Partnerships: Governance, Leadership, and Organizational Reform. 2014.

6. Beran D, Aebischer Perone S, Alcoba G, Bischoff A, Bussien C-L, Eperon G, et al. Partnerships in global health and collaborative governance: lessons learnt from the Division of Tropical and Humanitarian Medicine at the Geneva University Hospitals. Glob Health [Internet]. 2016 Dec [cited 2017 Oct 18];12(1). Available from:

http://globalizationandhealth.biomedcentral.com/articles/10.1186/s12992-016-0156-x. DOlhttps://doi.org/10.1186/s12992-016-0156-x

7. Paudel DR. Catastrophic Health Expenditure: An Experience from Health Insurance Program in Nepal. Emerg Sci J. 2019 Oct 1;3(5):327-36. DOI: 10.28991/esj-2019-01195

8. Peters DH, Tran NT, Adam T, Alliance for Health Policy and Systems Research, World Health Organization, editors. Implementation research in health: a practical guide. Geneva, Switzerland: World Health Organization; 201AD. 67 p. https://apps.who.int/iris/handle/10665/91758

9. Nilsen P. Making sense of implementation theories, models and frameworks. Implement Sci [Internet]. 2015 Dec [cited 2017 Oct 18];10(1). Available from: http://implementationscience.biomedcentral.com/articles/10.1186/s13012-015-0242-0.

10. Damschroder LJ, Aron DC, Keith RE, Kirsh SR, Alexander JA, Lowery JC. Fostering implementation of health services research findings into practice: a consolidated framework for advancing implementation science. Implement Sci [Internet]. 2009 Dec [cited 2017 Oct 18];4(1). Available from: http://implementationscience.biomedcentral.com/articles/10.1186/1748-5908-4-50

11. Means AR, Phillips DE, Lurton G, Njoroge A, Furere SM, Liu R, et al. The role of implementation science training in global health: from the perspective of graduates of the field's first dedicated doctoral program. Glob Health Action. 2016 Dec;9(1):31899. doi: 10.3402/gha.v9.31899

12. Palinkas LA, Fuentes D, Finno M, Garcia AR, Holloway IW, Chamberlain P. Inter-Organizational Collaboration in the Implementation of Evidence-based Practices Among Public Agencies Serving Abused and Neglected Youth. Adm Policy Ment Health Ment Health Serv Res. 2014 Jan;41(1):74-85. doi: 10.1007/s10488-012-0437-5

13. Henderson K, Gouglas D, Craw L. Gavi's policy steers country ownership and self-financing of immunization. Vaccine. 2016 Aug;34(37):4354-9. doi: 10.1016/j.vaccine.2016.06.014. 
14. Muraskin W. The global alliance for vaccines and immunization: Is it a new model for effective public-private cooperation in international public health? Am J Public Health. 2004;94(11):19221925. DOI: 10.2105/ajph.94.11.1922

15. Gupta Anuradha. Partners Engagement Framework and Alliance Accountability Framework [Internet]. Gavi, The Vaccine Alliance; 2016 [cited 2017 Oct 18]. Available from: http://www.gavi.org/support/pef/

16. Gandhi G. Charting the evolution of approaches employed by the Global Alliance for Vaccines and Immunizations (GAVI) to address inequities in access to immunization: a systematic qualitative review of GAVI policies, strategies and resource allocation mechanisms through an equity lens (1999-2014). BMC Public Health [Internet]. 2015 Dec [cited 2017 Oct 18];15(1). Available from: http://bmcpublichealth.biomedcentral.com/articles/10.1186/s12889-015-2521-8

17. Bloem P, Ogbuanu I. Vaccination to prevent human papillomavirus infections: From promise to practice. PLOS Med. 2017 Jun 27;14(6):e1002325. https://doi.org/10.1371/journal.pmed.1002325

18. Hanson C, Eckert L, Bloem P, Cernuschi T. Gavi HPV Programs: Application to Implementation. Vaccines. 2015 May 20;3(2):408-19. doi: 10.3390/vaccines3020408.

19. Shearer JC, Stack ML, Richmond MR, Bear AP, Hajjeh RA, Bishai DM. Accelerating Policy Decisions to Adopt Haemophilus influenzae Type b Vaccine: A Global, Multivariable Analysis. Klugman KP, editor. PLoS Med. 2010 Mar 16;7(3):e1000249. https://doi.org/10.1371/journal.pmed.1000249

20. Castro A, Cinà M, Helmer-Smith M, Vlček C, Oghor C, Cazabon D. A case study of Gavi'S human papillomavirus vaccine support programme. J Health Spec. 2017;5(1):2. DOI: 10.4103/24686360.198797

21. Jennings MC, Loharikar A. A Vaccine Against Cervical Cancer: Context for the Global Public Health Practitioner. Glob Health Sci Pract. 2018 Dec 27;6(4):629-34. https://doi.org/10.9745/GHSP-D-1800222

22. LaMontagne DS, Bloem PJN, Brotherton JML, Gallagher KE, Badiane O, Ndiaye C. Progress in HPV vaccination in low- and lower-middle-income countries. Int J Gynecol Obstet. 2017 Jul;138:7-14. DOI: 10.1002/ijgo.12186

23. Knoke D, Yang S. Social Network Analysis. 2nd ed. USA: SAGE; 2008. 133 p. (Quantitative Applications in the Social Sciences).

24. Sandström A, Carlsson L. The performance of policy networks: the relation between network structure and network performance. Policy Stud J. 2008;36(4):497-524. https://doi.org/10.1111/j.1541-0072.2008.00281.x

25. Brown CH, Kellam SG, Kaupert S, Muthén BO, Wang W, Muthén LK, et al. Partnerships for the Design, Conduct, and Analysis of Effectiveness, and Implementation Research: Experiences of the Prevention Science and Methodology Group. Adm Policy Ment Health Ment Health Serv Res. 2012 Jul;39(4):301-16. doi: 10.1007/s10488-011-0387-3.

26. De Brún A, McAuliffe E. Social Network Analysis as a Methodological Approach to Explore Health Systems: A Case Study Exploring Support among Senior Managers/Executives in a Hospital 
Network. Int J Environ Res Public Health. 2018 Mar 13;15(3):511. doi: 10.3390/ijerph15030511

27. Shearer JC, Dion M, Lavis JN. Exchanging and using research evidence in health policy networks: a statistical network analysis. Implement Sci [Internet]. 2014 Dec [cited 2019 May 16];9(1). Available from: http://implementationscience.biomedcentral.com/articles/10.1186/s13012-014-0126-8

28. Kamya C, Shearer J, Asiimwe G, Salisbury N, Waiswa P, Brinkerhoff J, et al. Evaluating Global Health Partnerships: A Case Study of a Gavi HPV Vaccine Application Process in Uganda. Int J Health Policy Manag. 2016 Oct 26;6(6):327-38. doi: 10.15171/IJHPM.2016.137

29. Human papillomavirus vaccines: WHO position paper, October 2014-Recommendations. Vaccine. 2015 Aug;33(36):4383-4.

30. Ai W. Participatory Action Research into Low Literates' Medical Needs in Rural Communities. SciMedicine J. 2019 Dec 1;1(4):176-88. DOI: 10.28991/SciMedJ-2019-0104-3

31. Miles MB, Huberman AM, Saldaña J. Qualitative data analysis: a methods sourcebook. 3rd ed. Los Angeles,CA: SAGE; 2014. 381 p.

32. Provan KG, Veazie MA, Staten LK, Teufel-Shone NI. The use of network analysis to strengthen community partnerships. Public Adm Rev. 2005;65(5):603-613. doi: 10.1111/j.15406210.2005.00487.x

33. Blanchet $K$, James P. How to do (or not to do) ... a social network analysis in health systems research. Health Policy Plan. 2012 Aug 1;27(5):438-46. doi: 10.1093/heapol/czr055.

34. Borgatti S. Ucinet for Windows: Software for Social Network Analysis. Harvard, MA: Analytic Technologies; 2002.

35. Borgatti S. NetDraw Software for Network Visualization. Lexington, KY: Analytic Technologies; 2002.

36. ISGlobal. Mozambique Hosts International Conference on Cervical Cancer in Africa. [cited 2017 Oct 19]; Available from: http://www.isglobal.org/en/-/mozambique-acoge-el-congreso-internacionalsobre-cancer-cervical-en-africa

37. Reagans R, McEvily B. Network structure and knowledge transfer: The effects of cohesion and range. Adm Sci Q. 2003;48(2):240-67. DOI: 10.2307/3556658

38. Mantel C, Wang SA. The privilege and responsibility of having choices: decision-making for new vaccines in developing countries. Health Policy Plan. 2012 May 1;27(suppl 2):ii1-4. doi: 10.1093/heapol/czs041.

39. Burchett HED, Mounier-Jack S, Griffiths UK, Biellik R, Ongolo-Zogo P, Chavez E, et al. New vaccine adoption: qualitative study of national decision-making processes in seven low- and middle-income countries. Health Policy Plan. 2012 May 1;27(suppl 2):ii5-16. doi: 10.1093/heapol/czs035.

40. Yousefi-Nooraie R, Dobbins M, Brouwers M, Wakefield P. Information seeking for making evidenceinformed decisions: a social network analysis on the staff of a public health department in Canada. BMC Health Serv Res [Internet]. 2012 Dec [cited 2020 May 13];12(1). Available from: https://bmchealthservres.biomedcentral.com/articles/10.1186/1472-6963-12-118 
41. Quinlan E, Robertson S. The communicative power of nurse practitioners in multidisciplinary primary healthcare teams: The communicative power of NPs. J Am Acad Nurse Pract. 2013 Feb;25(2):91102. https://doi.org/10.1111/j.1745-7599.2012.00768.x

42. Brinkerhoff JM. Assessing and improving partnership relationships and outcomes: a proposed framework. Eval Program Plann. 2002;25(3):215-231. DOI: 10.1016/S0149-7189(02)00017-4

43. Heijmans $\mathrm{N}$, van Lieshout $\mathrm{J}$, Wensing $\mathrm{M}$. Information exchange networks of health care providers and evidence-based cardiovascular risk management: an observational study. Implement Sci [Internet]. 2017 Dec [cited 2020 May 13];12(1). Available from: http://implementationscience.biomedcentral.com/articles/10.1186/s13012-016-0532-1

44. Mascia D, Cicchetti A. Physician social capital and the reported adoption of evidence-based medicine: Exploring the role of structural holes. Soc Sci Med. 2011 Mar;72(5):798-805. doi: 10.1016/j.socscimed.2010.12.011.

\section{Tables}

Table 1: Gavi FCE partnership framework dimensions' description

ntextual factors and prerequisites: Identification of the governmental and non-governmental stitutions and organizations as well as individuals involved in implementation of the pzambique HPV vaccine demonstration project. The origins of the partnership and how the oader political environment and the global Gavi Alliance partnership has influenced this. her Mozambique contextual factors that have facilitated or blocked the successful formation d performance of this partnership.

rtnership structure: Understanding the composition of the partnership's players and their lationships with each other, as well as the connections between the implementers of the HPV ccine demonstration project in the country.

rtner performance: Exploration of how effectively partners meet their deliverables and the echanisms for accountability.

rtnership practices: Investigation of the functionality of the whole partnership in terms of ofessional trust. Additionally, any formal and informal rules and processes that govern the rtnership; partners' competencies, capacities, roles and responsibilities, the partnership ordination mechanisms and management of the partnership.

rtnership's added value: Determination of partners' perceptions of outcomes of working together, mely efficiency, effectiveness and country ownership;

Table 2: Social Network Analyses hypotheses and metrics 
WHO health system governance characteristics hypotheses and measures for network connectivity

Characteristic 1: Capacity to effectively engage with and handle multiple scales (e.g. levels and sectors of the health system)

Reachability: Networks with a high level of reachability have the ability to access various sources of information.

Distance: The shorter the distance between the actors the faster the diffusion of information.

Networks with short average path length are more likely to facilitate the widespread

diffusion of information

Characteristic 2: Capacity to anticipate and cope with uncertainties and surprises

Centralization: A centralized structure has a higher capacity to coordinate actors and provide rapid response

Betweenness: Rapid response occurs when the key actors have the ability to reach all the players in the network

Characteristic 3: Capacity to combine and integrate different forms of knowledge

Reachability: The diversity of technical knowledge can be achieved through relationships with actors that belong to other spheres or subnetworks.

Density: Dense networks are more likely to facilitate the transfer of information however actors in a dense network have difficulty in accessing diverse forms of knowledge

Theory of network diffusion hypotheses and measures for network efficiency and effectiveness

Structural holes: Network with more structural holes is more efficient for the diffusion of information

Redundancy: Less redundancy means a more efficient network for the relaying

of information

Homophily: Novel information is more likely to enter heterogeneous networks while homophily in a network can be a barrier to accessing new information

Table 3: Organization affiliation of study participants

\begin{tabular}{lrr}
\hline Organization Type & Number & \multicolumn{1}{c}{$\%$} \\
\hline MOH NIP & 22 & 55 \\
$\quad$ National & 5 & 12.5 \\
\hline$\quad$ Provincial & 6 & 15 \\
\hline$\quad$ District & 11 & 27.5 \\
\hline MOE & 6 & 15 \\
\hline$\quad$ National & 1 & 2.5 \\
\hline$\quad$ Provincial & 2 & 5 \\
\hline$\quad$ District & 3 & 7.5 \\
\hline Multilateral & 3 & 7.5 \\
\hline CSO/NGO & 4 & 10 \\
\hline Research Institute & 3 & 7.5 \\
Bilateral & 1 & 2.5 \\
\hline Pharmaceutical & 1 & 2.5 \\
Total & 40 & $100 \%$
\end{tabular}

Table 4: Network topology measures 


\begin{tabular}{|c|c|c|}
\hline Metric & Value & Hypothesis (from Table 2) \\
\hline Nodes & 50 & \\
\hline Ties & 164 & \\
\hline $\begin{array}{l}\text { Distance } \\
\text { (average path } \\
\text { length) }\end{array}$ & 2.5 & $\begin{array}{l}\text { Networks with short average path length are more likely to } \\
\text { facilitate the widespread diffusion of information }\end{array}$ \\
\hline Reachability & 1 & $\begin{array}{l}\text { Networks with a high level of reachability have the ability to access } \\
\text { various sources of information }\end{array}$ \\
\hline Centralization & 0.483 & $\begin{array}{l}\text { A centralized structure has a higher capacity to coordinate actors } \\
\text { and provide rapid response }\end{array}$ \\
\hline Betweenness & 37.24 & $\begin{array}{l}\text { Rapid response occurs when the key actors have the ability to } \\
\text { reach all the players in the network }\end{array}$ \\
\hline Density & 0.1338 & $\begin{array}{l}\text { Dense networks are more likely to facilitate the transfer of } \\
\text { information however actors in a dense network have difficulty in } \\
\text { accessing diverse forms of knowledge }\end{array}$ \\
\hline $\begin{array}{l}\text { Structural } \\
\text { holes }\end{array}$ & $85 \%$ & $\begin{array}{l}\text { Network with more structural holes is more efficient for the } \\
\text { diffusion of information }\end{array}$ \\
\hline Redundancy & $70 \%$ & $\begin{array}{l}\text { Less redundancy means a more efficient network for the relaying } \\
\text { of information }\end{array}$ \\
\hline $\begin{array}{l}\text { Homophily E-I } \\
\text { index }\end{array}$ & 0.195 & $\begin{array}{l}\text { Novel information is more likely to enter heterogeneous networks } \\
\text { while homophily in a network can be a barrier to accessing new } \\
\text { information }\end{array}$ \\
\hline $\begin{array}{l}\text { Average tie } \\
\text { weight } \\
\text { (reported } \\
\text { trust) }\end{array}$ & 4.056 & \\
\hline
\end{tabular}

Table 5: Perceived benefits of partnership $(n=34)$ 


\begin{tabular}{|l|l|}
\hline Benefits: & $\begin{array}{l}\% \text { of respondents who } \\
\text { agreed }\end{array}$ \\
\hline Effectiveness & $100 \%$ \\
\hline Better able to execute activities & $100 \%$ \\
\hline Planned activities were executed with greater quality & $97 \%$ \\
\hline $\begin{array}{l}\text { Better able to identify the need for, and to acquire additional } \\
\text { support }\end{array}$ & $100 \%$ \\
\hline $\begin{array}{l}\text { Better able to respond to existing challenges, or those that arose } \\
\text { during the process }\end{array}$ & $91 \%$ \\
\hline Increased sustainability of immunization program & $97.6 \%$ \\
\hline Mean Effectiveness & $94 \%$ \\
\hline Efficiency & $88 \%$ \\
\hline More timely execution of planned activities & $74 \%$ \\
\hline Leveraged each organizations' comparative advantages & $62 \%$ \\
\hline Reduction in financial cost of process & $79.5 \%$ \\
\hline Better allocation of each organization's financial resources & \\
\hline Mean Efficiency & $79 \%$ \\
\hline Country Ownership & $91 \%$ \\
\hline Increased country ownership & $74 \%$ \\
\hline Increased transparency among partners & $94 \%$ \\
\hline Increased accountability among partners & $91 \%$ \\
\hline Increased legitimacy of decisions made & $85.8 \%$ \\
\hline Increased fairness of decisions made & \\
\hline Mean country ownership & $9 \%$ \\
\hline Drawbacks: & $6 \%$ \\
\hline Effectiveness & $7.5 \%$ \\
\hline Strained relations within my organization & $24 \%$ \\
\hline Created competition and conflict among member organizations & $6 \%$ \\
\hline Mean Effectiveness drawbacks & $21 \%$ \\
\hline Efficiency & $17 \%$ \\
\hline Unnecessary management burden on my organization & $24 \%$ \\
\hline Loss of control/autonomy over decisions & $24 \%$ \\
\hline $\begin{array}{l}\text { Forced us to make decisions in a way which was not natural/typical } \\
\text { for our organization }\end{array}$ & \\
\hline Mean Efficiency drawbacks & \\
\hline Country Ownership & \\
\hline Not enough credit given to my organization & \\
\hline Total Country Ownership drawbacks & \\
\hline
\end{tabular}

\section{Figures}




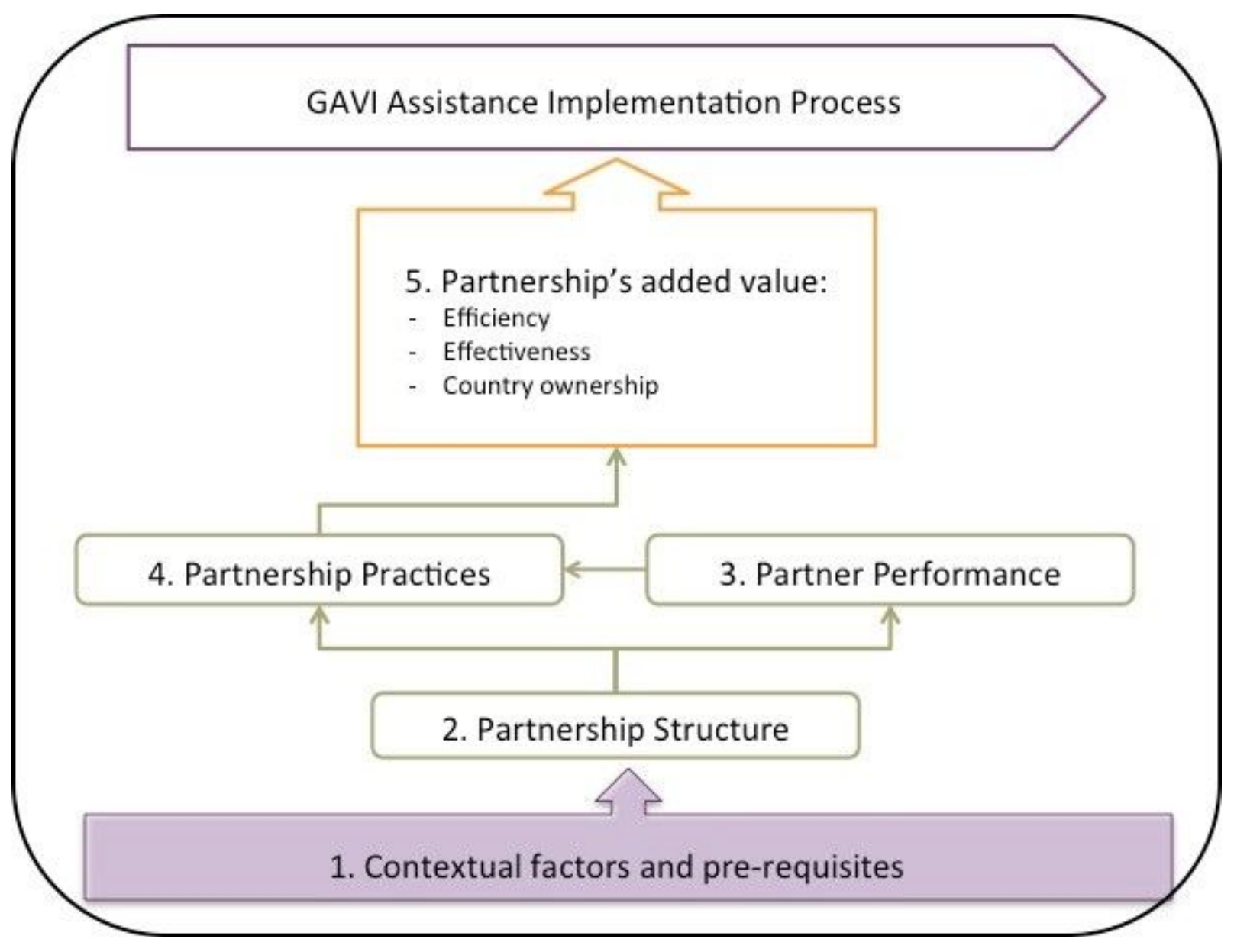

Figure 1

The Gavi FCE partnership evaluation framework 


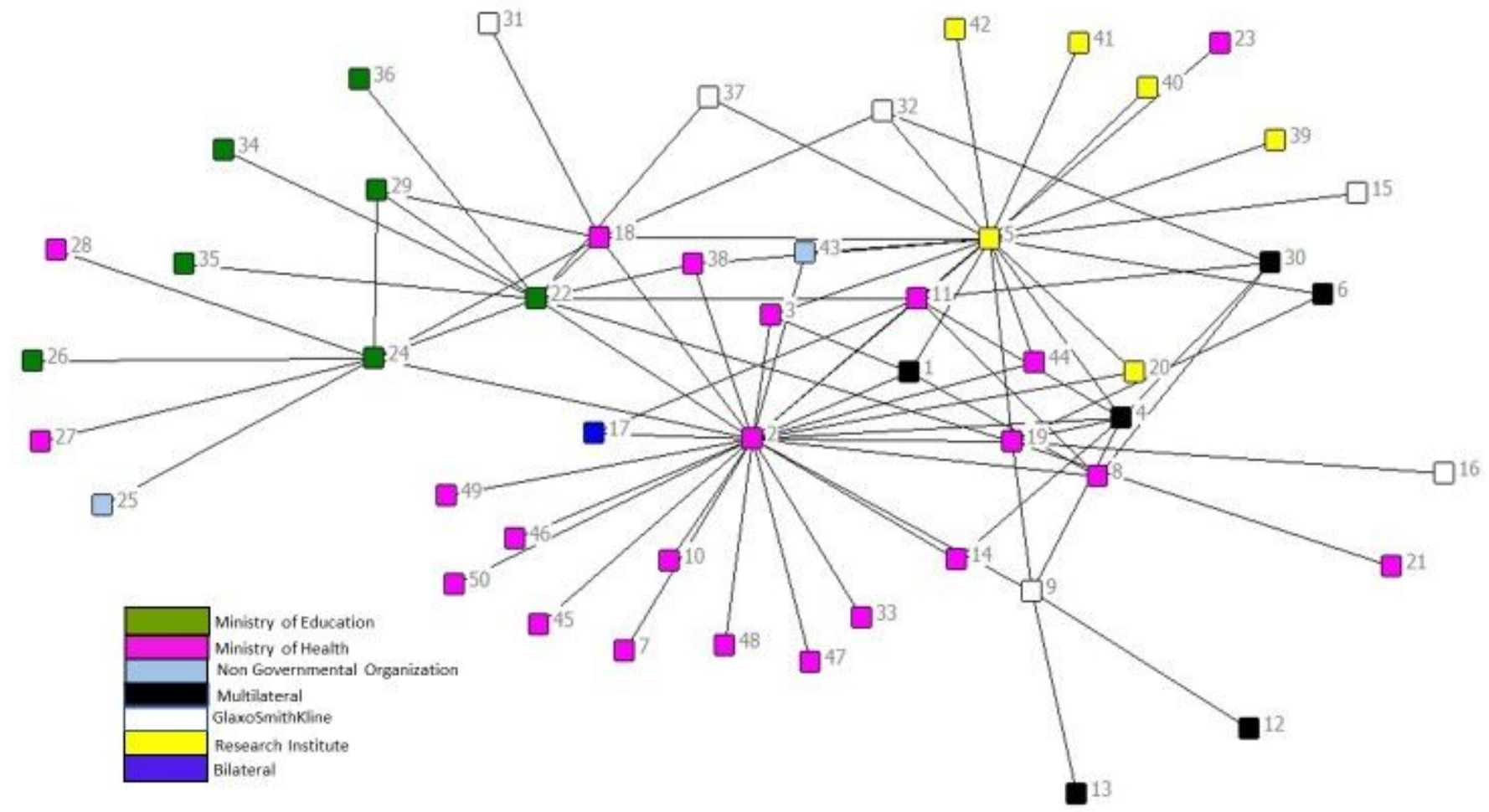

Figure 2

Research methods and partnership dimensions studied

Figure 3 not provided by the author.

Figure 3

Figure 3 was not provided by the author. 